\title{
Bone mineral density in old age: the influence of age at menarche, menopause status and habitual past and present physical activity
}

\author{
Anna Kopiczko
}

Department of Anthropology and Health Promotion, Faculty of Biomedical Sciences, Józef Piłsudski University of Physical Education, Warsaw, Poland

Submitted: 17 October 2018

Accepted: 9 December 2018

Arch Med Sci 2020; 16 (3): 657-665

DOI: https://doi.org/10.5114/aoms.2019.81314

Copyright @ 2019 Termedia \& Banach

\section{Abstract}

Introduction: In this study, the hypothesis that bone mineral density (BMD) of peri-, pre- and postmenopausal women is associated with the current level of habitual physical activity, as well as past physical activity, at the age of building peak bone mass, was tested.

Material and methods: The study involved 500 Polish women aged 40 to 70. For the assessment of BMD and bone mineral content (BMC) the densitometry method (dual-energy X-ray absorptiometry, DXA) of the forearm bone was used. The International Physical Activity Questionnaire (IPAQ) was used to assess the present level of physical activity. The assessment of past physical activity was related to adolescence.

Results: There was a significant, strong influence on the norm BMD in the distal forearm sections values in the distal forearm sections of such variables as: older age of the first menstruation $(O R=1.37 ; p=0.002)$, sufficient present physical activity $(\mathrm{OR}=1.57 ; p=0.001)$, and particularly high past physical activity $(\mathrm{OR}=6.77 ; p=0.003)$. Significantly lower chances for the norm BMD dis were found in women with the oldest hormonal status $(\mathrm{OR}=0.09 ; p<0.001)$. In the proximal segment, the analogous conditions of the norm BMD, and in addition the chances for good mineralization, were increased by higher body mass index $(O R=1.11 ; p<0.001)$. Sufficient present activity increased the chances of good forearm mineralization in the proximal part more than four times $(\mathrm{OR}=4.2 ; p<0.001)$, and a high level of past physical activity increased these chances several dozen times (OR $=69.9 ; p<0.001)$.

Conclusions: Physical activity proved to be one of the most important factors determining the statistically significant correct mineralization of bone tissue of women.

Key words: physical activity, bone mineral density, women's health, menarche, menopausal status.

\section{Introduction}

The skeleton is a unique structure that provides physical support for soft tissues and at the same time is responsible for the mineral balance of the system. The good condition of the skeleton depends on its hardness and resistance to fractures. Measures of bone tissue condition and

\author{
Corresponding author: \\ Anna Kopiczko PhD \\ Department \\ of Anthropology and \\ Health Promotion \\ Faculty of Biomedical \\ Sciences \\ Józef Piłsudski University \\ of Physical Education \\ 34 Marymoncka St \\ 00-968 Warsaw, Poland \\ Phone: +48 513104468 \\ E-mail: anka_kopiczko@ \\ interia.pl
}


its strength properties for external loads are the bone mass, its volume (geometry) and internal structure (trabeculae, collagen crosslinking and cortical bone thickness) [1].

These structures are constantly changing (remodelling) with age. In the case of women aged from around 40 to menopause, the physiological loss of the cortical bone is from $0.3 \%$ to $0.5 \%$, and the trabecular bone from $3 \%$ in the spine and $0.5 \%$ in the proximal femur per year $[2,3]$.

After the menopause, the process of bone mass loss accelerates to about 2-3\% annually, and if a women has risk factors for developing osteoporosis, then the bone destruction processes prevail over the bone formation processes. This results in the development of osteoporosis, i.e. bone thinning. The female hormonal system deeply affects the skeleton during its longitudinal and lateral construction during growth and development and during modelling and remodelling in adult life. Skeletal growth occurs before menstruation under the influence of growth hormone, insulin-like growth factors and other factors. The occurrence of oestrogen and other sex hormones from menarche around $11-13$ years stimulates the rapid deposition of bone minerals, as well as further skeletal growth for the next 10 years. Women reach about one third of peak bone mineral density (BMD) within 4 years of the onset of menarche. Early rapid growth of $B M D$ in adolescence causes a further slower increase in BMD and consolidation of skeletal minerals in late adolescence and at the beginning of the third cycle, to reach peak BMD at $25-35$ years of age $[4,5]$. After this period, there is a physiological loss of BMD, although at different rates depending on many environmental factors, particularly related to lifestyle, nutrition, and physical activity [6].

It is important to identify those factors which determine the inhibition or slowing down of the physiological process of bone mass loss in order to effectively prevent osteoporotic bone fractures, especially in perimenopausal women. Among these factors, undoubtedly, physical activity arouses great interest of scientists, as one of the modifiable factors conditioning the proper development of the skeleton [7]. The relationship between physical activity and mineral bone density has been investigated in various ways in epidemiological studies [8] and interventional studies [9]. Although the results of the studies were not always consistent, the exercises mainly with the load, from the point of view of impact and pressure on the bone and resistance movement, seem to be effective in maintaining bone mass, and thus in reducing the relative risk of fractures [10]. Physical activity systematically gives good physical fitness, and hence an efficient muscular system, which provides the necessary mechanical stress for good bone tissue growth [11]. The dose-response issues remain unexplained. Resistance exercises that load the axial skeleton are indicated as beneficial for the bones, and complex forms of exercises with an extensive structure of motion [12].

During physical activity of the skeleton, two types of mechanical stimuli interact - the forces exerted by the joint force reaction (JFR) and the forces associated with the ground force reaction (GFR). The strongest osteogenic effect was observed after moderate or high intensity exercise, in which both GFR and JFR forces work $[13,14]$.

Physical activity without GFR and JFR, such as swimming, seems to be the least appropriate in the prevention of BMD loss with age. According to the "mechanostat theory", skeletal consolidation is a manifestation of the mechanical adaptation of bone tissue to the increasing gradients of loads generated by muscle tissue [15]. The conversion of mechanical stimuli into biological signals, or the process of mechanotransduction, plays a fundamental role in the process of adapting the skeleton to current loads. Mechanotransduction depends on the close interaction of osteoblasts and osteocytes, which are mechano-sensitive cells. The mechanism of beneficial effects of mechanical loads on the skeletal system, as the authors emphasize, is complex [16].

Osteoporosis has become one of the main public health problems in the world. On a global scale, the health effects of osteoporosis affect about 200 million women [17]. We also know from various studies that recommendations for physical activity for health are often not prioritized in most populations of all ages.

Much is known about the role of physical activity in the prevention of osteoporosis and reducing the risk of falls. The level of BMD in athletes practising different sports is usually higher than in non-training peers. However, less is known about the determinants of BMD associated with physical activity, everyday life and not in regular training.

In this study, the hypothesis that BMD of peri-, pre- and postmenopausal women is associated with the current level of habitual physical activity, as well as past physical activity, at the age of building peak bone mass, was tested.

Physical activity may be an important element to consider in the prevention of osteopenia and osteoporosis in women.

\section{Material and methods}

\section{Subjects}

The study involved 500 Polish women aged 40 to 70. All examined women belonged to the Caucasian ethnic group. The sample size was cal- 
culated using the formula [18], taking into account the individual variability in BMD and the standard error, taken from published data, from a random sample of Polish women of similar age [19]. The sampling was taken from the list of population records from three districts of Warsaw: Bielany, Bemowo and Wola. The draws were made on the basis of data obtained from the Population Records Department of district offices (random-systematic selection was used, recruitment of every fifth woman from the register list), to obtain a planned sample number of 500 women.

All persons qualified for the study expressed their voluntary consent to participate in the project and were informed about the course of the study, as well as the possibility of withdrawal from participation in the project at any stage. Exclusion criteria included: thyroid and parathyroid disorders, cancers, rheumatoid arthritis, long-term steroid treatment, kidney disease, hormone replacement therapy.

The study group was divided into three subgroups depending on the hormonal status: premenopausal (87 women aged $41.9 \pm 2.5$ ), perimenopausal (130 women aged $48.2 \pm 3.1$ ) and postmenopausal status (283 women aged $56.8 \pm 6.2$, the average age of menopause was $49.1 \pm 3.1$ ).

The project received a positive opinion on the compliance with the rules of ethics of the Senate Ethics Committee for Scientific Research of the Academy of Physical Education of Joseph Pilsudski in Warsaw. The study was conducted and financed within the DM-14 project included in the statutory activities of the Józef Pitsudski University of Physical Education in Warsaw, in Poland.

\section{Hormonal status}

Age of menarche was asked at the baseline interview. Hormonal status was assessed on the basis of self-assessment using the World Health Organization classification. Premenopause was characterized by a rhythmic menstrual cycle. Perimenopause (the period immediately preceding the menopause) was characterized by prolonged, irregular menstrual cycles, or end of menstrual bleeding, but at the time of the last menstrual period, 12 consecutive months without bleeding (amenorrhea). Natural menopause (postmenopause) is the period after the last woman's menstrual period after 12 consecutive months without bleeding [20, 21].

\section{Anthropometric measurement}

The basic body dimensions and indicators were assessed using the anthropometric measurements. The body height, body weight and the needs for the densitometry study of the forearm of the non-dom- inant limb were measured. Body mass index (BMI) indices were calculated. All measurements were performed according to the applicable methodology and with the same measurement instruments [22].

\section{Bone density measurement}

For the assessment of BMD and bone mineral content (BMC) the densitometry method of the forearm bone was used (at two measurement points: proximal and distal): dual-energy X-ray absorptiometry (DXA), with the NORLAND company apparatus. There were two measurement points: the proximal and the distal part of bone according to the adopted densitometry methodology. The Norland DXA has a global distal site (radius + ulna), global proximal site (radius + ulna), and a $1 / 3$ proximal radius site. Regression statistics are reported for all similar regions of interest (ROIs). The distal ROI spans $10 \mathrm{~mm}$ of the lowest BMD region in the distal forearm and is found using an automated search routine. The proximal site spans $10 \mathrm{~mm}$ starting at the $1 / 3$ forearm length and continuing proximally [23]. The study was conducted in all people using the same equipment by a team having the necessary qualifications and experience in the research with the above-mentioned method and apparatus. The scanner was calibrated daily against the standard calibration block supplied by the manufacturer to control for possible baseline drift. All the data were collected according to the recommendations of the International Society for Clinical Densitometry.

\section{Evaluation of physical activity}

The International Physical Activity Questionnaire (IPAQ) was used to assess the present level of physical activity in a direct interview by a trained interviewer [24]. Weekly physical activity in the form of energy expenditure was calculated according to Biernat et al. [25]. The Metabolic Equivalent Task (MET) values obtained during intense, moderate and walking activity were summarized. Activities undertaken throughout the week were taken into account.

The short version (9 items) provided information on the time spent walking, in vigorous and moderate intensity activity and in sedentary activity. Participants were instructed to refer to all domains of physical activity. Intensity of effort was determined by metabolic equivalent (MET) where 1 MET corresponds to $\mathrm{O}_{2}$ consumption at rest and is $3.5 \mathrm{ml} \mathrm{O} / \mathrm{kg}$ body weight/min. The authors rated 3.3 MET for low intensity exercise, 4 MET for moderate and 6 MET for intensive [25].

The classification of physical activity level based on energy expenditure was adopted according to Biernat et al. Activity was insufficient when total 
energy expenditure was less than 600 MET min/ day, sufficient when between 600 and 1500 MET $\mathrm{min} /$ day and high when total energy expenditure exceeded 1500 MET min/day. The results of physical activity assessment were referenced to the recommendations of the American College of Sport Medicine and WHO [26, 27] for adults.

The assessment of past physical activity was related to adolescence, that is the period of peak bone mass. In a direct interview, data were collected on the participation of adolescent girls in school and off-campus sports. Based on responses from the respondents, the classification used was inactive, moderately active (participation in physical education classes) and high physical activity (training in various sports disciplines).

\section{Statistical analysis}

All calculations and analyses were performed using the Statistica software program (v. 11, StatSoft. USA). The normality of distribution was verified by the Shapiro-Wolf test, the assumption of equality of variance with the Levene test. The data analysis was based on the factor analysis of variance (ANOVA) and the Bonferroni (post hoc) test. Measures of magnitude (effect force) are shown with the help of the eta-square $\left(\eta^{2}\right)$. Effect size was calculated as an $\eta^{2}$ (small effect: < 0.01; medium effect: 0.01-0.06; large effect: > 0.14). In addition, in order to indicate an independent association of the correct bone tissue mineralization with individual factors, multivariate analysis was used - backward stepwise logistic regression. The chance of occurrence of bone mineralization in the standard (OR) was assessed with a 95\% confidence interval. The logistic regression model used the $R^{2}$ Nagelkerke coefficient formula. The significance of the regression coefficient was assessed using the Wald-Wolfowitz series test. The level of significance was assumed as the $p$-value $<0.05$.

\section{Results}

The general characteristics of the 500 women, stratified by menopausal status, are shown in Table I. Women in peri- and premenopause were statistically significantly older in the first menstrual period $\left(p<0.001 ; \eta^{2}=0.10\right)$ and had higher body height compared to women in postmenopausal age $\left(p<0.001 ; \eta^{2}=0.07\right)$. Younger hormonal age strongly and significantly conditioned better BMD in the distal $\left(p<0.001 ; \eta^{2}=0.12\right)$ and proximal $\left(p<0.001 ; \eta^{2}=0.19\right)$ segments. Analogous relations were noted for BMC in the distal $(p<0.001$; $\left.\eta^{2}=0.13\right)$ and proximal parts $\left(p<0.001 ; \eta^{2}=0.10\right)$. Women at a younger hormonal age (pre- and peri-) had significantly higher present physical activity in total $\left(p<0.01 ; \eta^{2}=0.04\right)$, as well as intense $\left(p<0.001 ; \eta^{2}=0.07\right)$ and moderate $\left(p<0.01 ; \eta^{2}=\right.$ 0.02 ) compared to postmenopausal women (Table I).

Women active throughout their lives had significantly higher BMD dis. compared to inactive women throughout their lives and active only in the past $\left(p<0.001 ; \eta^{2}=0.09\right)$, as well as active only now $\left(p<0.05 ; \eta^{2}=0.09\right)$. In the proximal segment, this relationship was even stronger $\left(p<0.001 ; \eta^{2}=0.27\right)$. In the case of the proximal segment, also physical activity only in the past determined significantly greater BMD compared to women inactive throughout their whole lives with a significant level of this effect $\left(p<0.001 ; \eta^{2}=\right.$ 0.27 ). Analogous relations were noted for BMC. Physical activity throughout the whole life conditioned the highest BMC in both sections of the measurement. Women who have been inactive in the past now have the smallest BMC dis. and prox. (Table II).

The results obtained from the stepwise backward logistic regression model indicate a significant, strong influence on the norm BMD in the distal part of forearm of such variables as: older age of the first menstruation $(\mathrm{OR}=1.37 ; p=0.002)$, sufficient present physical activity $(\mathrm{OR}=1.57$; $p=0.001)$, and especially high past physical activity $(\mathrm{OR}=6.77 ; p=0.003)$. Significantly lower chances for the norm BMD dis were found in women with the oldest hormonal status $\mathrm{OR}=0.09$; $p<0.001)$. In the proximal segment similar conditions of BMD were visible in the case of the first menarche age and hormonal status, and in addition the chances of good mineralization in this section increased the higher $\mathrm{BMI}(\mathrm{OR}=1.11$; $p<0.001)$. However, the largest and strongly significant odds ratio for norm BMD prox. was conditioned by physical activity. Sufficient present activity increased the chances of good forearm mineralization in the proximal part more than four times $(\mathrm{OR}=4.2 ; p<0.001)$, and the high level of past physical activity increased these chances several dozen times $(\mathrm{OR}=69.9 ; p<0.001)$ (Table III).

\section{Discussion}

In this study, selected conditions of BMD and $B M C$ of the forearm in women were analyzed. In particular, a modifiable factor was taken into account related to the lifestyle, that is, the past, present and life physical activity. Then, the biological factor, the age of the first menstruation and the hormonal status of women, including the pre- and postmenopausal stages, had a strong influence on BMD. Younger hormonal age strongly and significantly conditioned better mineralization of bone tissue BMD in both sections of the measurement. Analogous relations were noted for BMC. Women active throughout their lives had significantly higher BMD compared to those inac- 
Table I. Characteristics of study population

\begin{tabular}{|c|c|c|c|c|}
\hline Variable & $\begin{array}{c}\text { Premenopausal } \\
\text { women }(n=87) \\
\text { Mean } \pm \text { SD }\end{array}$ & $\begin{array}{l}\text { Perimenopausal } \\
\text { women }(n=130) \\
\text { Mean } \pm \text { SD }\end{array}$ & $\begin{array}{c}\text { Postmenopausal } \\
\text { women }(n=283) \\
\text { Mean } \pm \text { SD }\end{array}$ & $F(p)$ \\
\hline $\begin{array}{l}\text { Age of first menstruation } \\
\text { [years] }\end{array}$ & $14.7 \pm 1.44$ & $14.6 \pm 1.39$ & $13.7 \pm 1.37$ & $\begin{aligned} & 28.47 \\
(a, b & <0.001) \\
(c & >0.05)\end{aligned}$ \\
\hline Weight [kg] & $73.2 \pm 14.5$ & $70.8 \pm 12.3$ & $72.2 \pm 13.0$ & $\begin{array}{c}0.83 \\
(\mathrm{a}, \mathrm{b}, \mathrm{c}>0.05)\end{array}$ \\
\hline Height $[\mathrm{cm}]$ & $165.5 \pm 5.2$ & $163.7 \pm 5.3$ & $161.5 \pm 5.6$ & $\begin{aligned} & 19.40 \\
(a, b & <0.001) \\
(c & >0.05)\end{aligned}$ \\
\hline $\mathrm{BMI}\left[\mathrm{kg} / \mathrm{m}^{2}\right]$ & $26.7 \pm 5.3$ & $26.4 \pm 4.2$ & $27.7 \pm 5.0$ & $\begin{aligned} & 3.25 \\
&(\stackrel{b}{ }<0.05) \\
&(a, c>0.05)\end{aligned}$ \\
\hline BMD dis. $\left[\mathrm{g} / \mathrm{cm}^{2}\right]$ & $0.384 \pm 0.07$ & $0.383 \pm 0.05$ & $0.333 \pm 0.07$ & $\begin{aligned} & 35.49 \\
(\mathrm{a}, \mathrm{b} & <0.001) \\
(\mathrm{c} & >0.05)\end{aligned}$ \\
\hline BMD prox. $\left[\mathrm{g} / \mathrm{cm}^{2}\right]$ & $0.779 \pm 0.06$ & $0.777 \pm 0.07$ & $0.698 \pm 0.09$ & $\begin{aligned} & 56.46 \\
&(\mathrm{a}, \mathrm{b}<0.001) \\
&(\mathrm{c}>0.05)\end{aligned}$ \\
\hline BMC dis. $[g]$ & $1.452 \pm 0.22$ & $1.495 \pm 0.21$ & $1.296 \pm 0.258$ & $\begin{aligned} & 36.31 \\
&(\mathrm{a}, \mathrm{b}<0.001) \\
&\left({ }^{c}>0.05\right)\end{aligned}$ \\
\hline BMC prox. [g] & $1.980 \pm 0.23$ & $2.000 \pm 0.21$ & $1.826 \pm 0.259$ & $\begin{aligned} & 29.0 \\
(a, b b & <0.001) \\
(c & >0.05)\end{aligned}$ \\
\hline T-score dis. & $0.619 \pm 1.36$ & $0.594 \pm 0.94$ & $-0.276 \pm 1.306$ & $\begin{aligned} & 31.38 \\
&(\mathrm{a}, \mathrm{b}<0.001) \\
&\left({ }^{c}>0.05\right)\end{aligned}$ \\
\hline T-score prox. & $-0.627 \pm 1.13$ & $-0.604 \pm 0.93$ & $-1.906 \pm 1.448$ & $\begin{aligned} & 62.50 \\
(a, b & <0.001) \\
(c & >0.05)\end{aligned}$ \\
\hline Present HPA in all (MET) & $1283.9 \pm 1288.7$ & $1353.7 \pm 1434.8$ & $777.2 \pm 1177.6$ & $\begin{array}{c}11.54 \\
\left({ }^{a}<0.01\right) \\
(b<0.001) \\
\left({ }^{c}>0.05\right)\end{array}$ \\
\hline Present HPA intensive (MET) & $201.4 \pm 395.7$ & $252.9 \pm 430.3$ & $56.8 \pm 217.0$ & $\begin{aligned} & 19.24 \\
(a, b & <0.001) \\
(c & >0.05)\end{aligned}$ \\
\hline $\begin{array}{l}\text { Present HPA moderate } \\
\text { (MET) }\end{array}$ & $626.2 \pm 1042.5$ & $700.5 \pm 1332.1$ & $364.3 \pm 845.7$ & $\begin{aligned} & 5.60 \\
(b & <0.01) \\
(a, c & >0.05)\end{aligned}$ \\
\hline $\begin{array}{l}\text { Present HPA locomotive } \\
(\mathrm{MET})\end{array}$ & $456.3 \pm 340.6$ & $400.3 \pm 335.7$ & $346.9 \pm 542.7$ & $\begin{array}{c}2.01 \\
(\mathrm{a}, \mathrm{b}, \mathrm{c}>0.05)\end{array}$ \\
\hline
\end{tabular}

$B M D$ - bone mineral density, BMC - bone mass, dis. - distal point of forearm, prox. - proximal point of forearm, BMI - body mass index, HPA - habitual physical activity, MET - metabolic equivalent; ${ }^{a}$ significant difference between premenopause vs. postmenopause; ${ }^{b}$ significant difference between perimenopause vs. postmenopause; 'significant difference between premenopause vs. perimenopause.

tive throughout their lives and active only in one of the analyzed stages of life (only in the past, in the age of building peak bone mass or only now, in the physiological loss of BMD). Analogous relations were noted for BMC, where physical activity throughout the whole life conditioned the highest BMC. The results obtained from the logistic regression model indicate that significantly higher odds (OR) on the correct BMD values of the forearm in adulthood were found in women who had the first menstruation later. Significant chances of proper bone mineralization were increased by sufficient physical activity, especially its high level in the past. In addition, in the proximal segment the BMD norm was increased by a higher BMI. However, the largest and strongly significant effect to norm BMD dis and prox. has a physical activity throughout life.

Drenjancevic et al. [28] as well as Tucker et al. [29] pointed to physical activity as the most important factor conditioning the adaptation of bone tissue to changes in bone mechanical loads as a result of daily 
Table II. Bone mineral density and bone mass in the proximal and distal point of the forearm bone in relation to the physical activity throughout life in Polish women

\begin{tabular}{|c|c|c|c|c|c|}
\hline \multirow[t]{2}{*}{ Variable } & \multicolumn{4}{|c|}{ Level of physical activity for life in Polish women $(n=500)$} & \multirow[t]{2}{*}{$F(p)$} \\
\hline & $\begin{array}{c}\text { Inactive for life } \\
(n=37) \\
\text { Mean } \pm \text { standard } \\
\text { deviation (median) }\end{array}$ & $\begin{array}{l}\text { Active only in the } \\
\text { past }(n=228) \\
\text { Mean } \pm \text { standard } \\
\text { deviation (median) }\end{array}$ & $\begin{array}{l}\text { Active only now } \\
\quad(n=14) \\
\text { Mean } \pm \text { standard } \\
\text { deviation (median) }\end{array}$ & $\begin{array}{l}\text { Active throughout } \\
\text { life }(n=221) \\
\text { Mean } \pm \text { standard } \\
\text { deviation (median) }\end{array}$ & \\
\hline $\begin{array}{l}\text { BMD dis. } \\
{\left[\mathrm{g} / \mathrm{cm}^{2}\right]}\end{array}$ & $\begin{array}{l}0.314 \pm 0.07 \\
(0.302)\end{array}$ & $\begin{array}{c}0.340 \pm 0.075 \\
(0.335)\end{array}$ & $\begin{array}{c}0.327 \pm 0.051 \\
(0.342)\end{array}$ & $\begin{array}{c}0.378 \pm 0.060 \\
(0.375)\end{array}$ & $\begin{aligned} & 16.84 \\
(c, e & <0.001) \\
\left({ }^{f}\right. & <0.05) \\
(\mathrm{a}, \mathrm{b}, \mathrm{d} & >0.05)\end{aligned}$ \\
\hline $\begin{array}{l}\text { BMD prox. } \\
{\left[\mathrm{g} / \mathrm{cm}^{2}\right]}\end{array}$ & $\begin{array}{c}0.639 \pm 0.085 \\
(0.649)\end{array}$ & $\begin{array}{c}0.701 \pm 0.087 \\
(0.707)\end{array}$ & $\begin{array}{c}0.691 \pm 0.050 \\
(0.684)\end{array}$ & $\begin{array}{c}0.783 \pm 0.069 \\
(0.782)\end{array}$ & 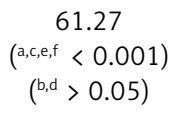 \\
\hline $\begin{array}{l}\text { BMC dis. } \\
{[\mathrm{g}]}\end{array}$ & $\begin{array}{c}1.201 \pm 0.242 \\
(1.185)\end{array}$ & $\begin{array}{c}1.306 \pm 0.257 \\
(1.307)\end{array}$ & $\begin{array}{c}1.229 \pm 0.167 \\
(1.242)\end{array}$ & $\begin{array}{c}1.484 \pm 0.216 \\
(1.497)\end{array}$ & $\begin{aligned} & 30.36 \\
&(\mathrm{c}, \mathrm{e}<0.001) \\
&\left({ }^{f}<0.01\right) \\
&(\mathrm{a}, \mathrm{b}, \mathrm{d}>0.05)\end{aligned}$ \\
\hline $\begin{array}{l}\text { BMC prox. } \\
{[\mathrm{g}]}\end{array}$ & $\begin{array}{c}1.652 \pm 0.297 \\
(1.688)\end{array}$ & $\begin{array}{c}1.833 \pm 0.239 \\
(1.835)\end{array}$ & $\begin{array}{c}1.773 \pm 0.160 \\
(1.780)\end{array}$ & $\begin{array}{c}2.015 \pm 0.210 \\
(2.036)\end{array}$ & $\begin{aligned} & 40.72 \\
(\mathrm{acce}, & <0.001) \\
\left({ }^{f}\right. & <0.01) \\
(\mathrm{b}, \mathrm{d} & >0.05)\end{aligned}$ \\
\hline
\end{tabular}

$B M D$ - bone mineral density, BMC - bone mass, dis. - distal point of forearm, prox. - proximal point of forearm; ${ }^{a}$ significant difference between inactive for life vs. active only in the past; ${ }^{b}$ significant difference between inactive for life vs. active only now; 'significant difference between inactive for life vs. active throughout life; ${ }^{d}$ significant difference between active only in the past vs. active only now; ${ }^{e}$ significant difference between active only in the past vs. active throughout life; fsignificant difference between active only now vs. active throughout life.

Table III. Multivariate analyses - stepwise logistic regression

\begin{tabular}{|c|c|c|c|c|c|c|}
\hline Variable & OR & $\begin{array}{c}95 \% \mathrm{Cl} \\
\text { lower }\end{array}$ & $\begin{array}{c}95 \% \mathrm{Cl} \\
\text { upper }\end{array}$ & $P$-value & $\chi^{2}$ Wald & $R^{2}$ Nagelkerke \\
\hline \multicolumn{7}{|l|}{ Norm BMD dis.: } \\
\hline Age of first menstruation & 1.37 & 1.116 & 1.671 & 0.002 & 9.15 & 0.348 \\
\hline BMI & 1.08 & 1.020 & 1.147 & 0.008 & 6.91 & \\
\hline Premenopause & 0.43 & 0.090 & 2.053 & 0.577 & 0.31 & \\
\hline Postmenopause & 0.09 & 0.028 & 0.310 & $<0.001$ & 20.6 & \\
\hline Sufficient present HPA & 2.81 & 1.488 & 5.312 & 0.001 & 10.14 & \\
\hline Moderate past HPA & 1.57 & 0.761 & 3.246 & 0.149 & 2.08 & \\
\hline High past HPA & 6.77 & 1.91 & 24.01 & 0.003 & 8.57 & \\
\hline \multicolumn{7}{|l|}{ Norm BMD prox.: } \\
\hline Age of first menstruation & 1.44 & 1.198 & 1.721 & $<0.001$ & 15.38 & 0.542 \\
\hline BMI & 1.11 & 1.051 & 1.167 & $<0.001$ & 14.71 & \\
\hline Premenopause & 0.86 & 0.415 & 1.793 & 0.157 & 1.99 & \\
\hline Postmenopause & 0.29 & 0.166 & 0.509 & $<0.001$ & 19.99 & \\
\hline Sufficient present HPA & 4.20 & 2.598 & 6.792 & $<0.001$ & 34.26 & \\
\hline Moderate past HPA & 6.96 & 2.183 & 22.18 & 0.599 & 0.275 & \\
\hline High past HPA & 69.9 & 19.01 & 257.3 & $<0.001$ & 56.05 & \\
\hline
\end{tabular}

OR - odds ratio, dis. - distal point of forearm, prox. - proximal point of forearm, BMI - body mass index, HPA - habitual physical activity.

life activity, as well as a protective predictor against bone loss and demineralization occurring with age. In a 2-year study of women by Kumar et al. [30], in the pre-menopausal period, it was found that physical activity can be considered as one of the important predictors of BMD. On the basis of linear regression analysis, it was shown that first of all physical activity of women was an important determinant 
of the norm BMD in both the lumbar spine and the femoral neck. Multivariate analysis of the above studies showed that in $34.6 \%$ bone density in the lumbar spine was determined by physical activity, age, BMI, energy intake, in the femoral neck only in $22.7 \%$ [30]. Cross-sectional studies of 5000 women in the period before and after menopause, conducted by Kim et al. [31] confirmed this thesis. It was demonstrated that BMD of the femur and lumbar spine was significantly higher in physically active women, showing the largest sum of metabolic equivalents, calculated on the basis of the activity questionnaire. It was found that regardless of menopausal status, moderate physical exercise in free time had a significant positive relationship with both BMD in the lumbar spine and femur. And in menopausal women who had physical activity at the level of 1,050-1,500 (MET-min/week), the highest BMD was found in both places of measurement [31]. Complementarily, a lack of physical activity is one of the most important factors causing the loss of bone mass and its density. The skeletal system that is not affected by physical effort loads is subject to faster BMD and BMC loss processes in mature women [32]. As other authors of research on factors determining bone mass density and mass emphasize, physical activity is important and has a beneficial effect on bone mass, its microarchitecture and resistance to mechanical injuries when it is undertaken systematically and throughout life [33, 34]. In our own studies, it was also found that active women throughout their lives were much less likely to undergo bone mineralization than inactive ones. The level of activity in youth was particularly significant as it conditioned the norm BMD and BMC of the examined women after 40 years of age. The continuation of an active lifestyle, in the subsequent stages of ontogenesis (after reaching peak bone mass), based on systematic physical activity in accordance with the recommendations, is associated with effective prophylaxis of osteopenia and osteoporosis [35]. Andreoli et al. [36] in a study of bone status of mature age in former sportsmen who in the past achieved mastery in various sports, stated that a high level of physical activity in adolescence but still active was associated with higher $\mathrm{BMD}$ and $\mathrm{BMC}$ compared to peers not training in youth. The role of physical activity for the proper physical development of children and adolescents is enormous and pleiotropic. It affects the proper functioning of many organs and systems, including support of the entire skeletal system.

In studies of Polish women, attention was also paid to the relationship between the state of bone tissue and the hormonal (menstrual) state of women. The women with the first menstrual period occurring later on were more likely to have normal BMD later. The older age of the first menstruation was significantly associated with higher bone BMD and BMC. This result is contrary to the reports of other authors. In a study of 1,782 postmenopausal women, it was found that the later age of the first menarche significantly increased the risk of osteoporosis in the lumbar spine compared to women characterized by a younger age of the first menarche. However, this relationship was associated with the onset of early menopause in these women. The sum of these conditions gave a higher degree of risk of osteoporosis [37]. Events affecting circulating endogenous levels of oestrogen, such as menopause, first menarche, pregnancy and lactation, and sources of exogenous oestrogen, such as oral contraceptives and postmenopausal hormones, have been evaluated as determinants of bone tissue condition in women. Menopause, which is characterized by a decrease in oestrogen production, has the largest share in reducing BMD. Earlier age of menopause is associated with an increased risk of osteoporosis [38]. The occurrence of menarche is associated with many physiological changes in the body of women, including the secretion of oestrogen from the ovaries. It is estimated that women reach $1 / 3$ of their peak BMD with the occurrence of menarche [5]. Earlier age of menarche associated with higher circulating oestrogen concentrations may have a protective effect against the development of osteoporosis. Conversely, early menopause presents an increased risk of osteoporosis and its clinical complications and is associated with increased bone fragility and susceptibility to low-energy fractures at a later age $[39,40]$. In our own research, the reverse result was obtained. Menarche at a later age determined the norm BMD. Howev$\mathrm{er}$, in the case of a relationship between the condition of the bone and the onset of menopause, according to the study of other authors, women in the postmenopausal period were particularly at risk of weight loss and bone mineralization.

The problem of bone density tests in women is current and it is necessary to thoroughly understand the risk factors of osteopenia and osteoporosis. Interesting new directions of research include the assessment of the influence of alcohol, coffee, and tea on BMD [41], quality of life [42], as well as detailed studies of the relationship between BMD and other diseases [43] and with biomarkers in blood [44].

The study has some limitations. Certainly, the results relate to women aged only from 40 to 70. It would be worth expanding the research to a population of younger women. The project involved women living in a large urban area, so the results should be verified by research conducted on females from smaller towns, outside central Poland. Test results give a realistic measurement 
of the bone mass and bone mineral density in the forearm bone. It would be interesting to continue research about $B M D$ and $B M C$ in the whole skeleton.

In conclusion, physical activity proved to be one of the most important factors determining the statistically significant correct mineralization of bone tissue of women. It has been shown that the chance of optimum mineralization increased significantly especially in women who were physically active throughout their lives. The results obtained in this study indicate the need to extend the scope of BMD conditions research with further analysis regarding the effects of physical activity and its relation to BMD and BMC.

A practical application of the research results is a recommendation for the implementation of physical activity programmes aimed at the prevention of osteopenia and osteoporosis. In addition, it is recommended to undertake educational programmes in all types of school about the role of physical activity throughout life, and its impact on building the correct mass and optimal bone mineralization for women.

\section{Conflict of interest}

The author declares no conflict of interest.

\section{References}

1. Seeman E. Bone modeling and remodeling. Crit Rev Eukaryot Gene Expr 2009; 19: 219-33.

2. Rauch F, Schoenau E. Changes in bone density during childhood and adolescence: an approach based on bone's biological organization. J Bone Miner Res 2001; 16: 597-604.

3. Schoenau E, Rauch F. Biochemical markers of bone metabolism. In: Pediatric Bone. Glorieux FH, Pettifor J, Jueppner H (eds). Academic Press San Diego, CA, USA 2003; 339-57.

4. Wang O, Nicholson PH, Suuriniemi M, et al. Relationship of sex hormones to bone geometric properties and mineral density in early pubertal girls. J Clin Endocrinol Metab 2004; 89: 1698-703.

5. Clarke BL, Khosla S. Female reproductive system and bone. Arch Biochem Biophys 2010; 503: 118-28.

6. Kopiczko A. Assessment of intake of calcium and vitamin D and sun exposure in the context of osteoporosis risk in a study conducted on perimenopausal women. Menopause Rew 2014; 13: 79-83.

7. Nguyen TV, Sambrook PN, Eisman JA. Bone loss, physical activity, and weight chase in elderly women: the Dubbo osteoporosis epidemiology study. J Bone Miner Res 1998; 13: 1458-67.

8. Krumm EM, Dessieux OL, Andrews P, Thompson DL. The relationship between daily steps and body composition in postmenopausal women. J Womens Health 2006; 15: 202-10.

9. Von Stengel S, Kemmler W, Bebenek M, Engelke K, Kalender WA. Effects of whole-body vibration training on different devices on bone mineral density. Med Sci Sports Exerc 2011; 43: 1071-9.
10. Kohrt WM, Bloomfield SA, Little KD, Nelson ME, Yingling VR. Physical activity and bone health. Med Sci Sports Exerc 2004; 36: 1985-96.

11. Zhao R, Zhao M, Zhang L. Efficiency of jumping exercise in improving bone mineral density among premenopausal women: a meta-analysis. Sports Med 2014; 44: 1393-402.

12. Muir JM, Ye C, Bhandari M, Adachi JD, Thabane L. The effect of regular physical activity on bone mineral density in post-menopausal women aged 75 and over: a retrospective analysis from the Canadian multicentre osteoporosis study. BMC Musculoskelet Disord 2013; 14: 253-63.

13. Kemmler W, Weineck J, Kalender WA, Engelke K. The effect of habitual physical activity, non-athletic exercise, muscle strength, and $\mathrm{VO}_{2} \max$ on bone mineral density is rather low in early postmenopausal women. J Musculosceletal Neuron Interact 2004; 4: 325-34.

14. Matsuo K. Cross-talk among bone cells. Curr Opin Nephrol Hypertens 2009; 18: 292-7.

15. Frost HM. The Utah paradigm of skeletal physiology: an over view of its insights for bone, cartilage and collagenous tissue organs. J Bone Miner Metab 2000; 18: 305-16.

16. Isaksson H, Gröngröft I, Wilson W, et al. Remodeling of fracture callus in mice is consistent with mechanical loading and bone remodeling theory. J Orthop Res 2009; 27: 664-72.

17. Kanis JA. Assessment of osteoporosis at the primary health-care level. WHO Technical Report, University of Sheffield, UK, World Health Organization Collaborating Centre for Metabolic Bone Diseases 2007; 1-339.

18. Gibson R. Principles of Nutritional Assessment. $2^{\text {nd }}$ edn. Oxford University Press 2005.

19. Chabros E, Rogalska Niedźwiedź M, Wajszczyk B, Chwojnowska Z, Charzewska J, Kost J. Stan odżywienia kobiet w wieku okołomenopauzalnym i pomenopauzalny. Żyw Człow Metab. Żyw Człow Metab 2003; 1: 464-7.

20. World Health Organization: Research on the menopause: report of a WHO Scientific Group. WHO Technical Report Series np. 670, Geneva, Switzerland 1981.

21. O'Connor KA, Holman DJ, Wood JW. Menstrual cycle variability and the perimenopause. Am J Hum Biol 2001; 13: 465-78

22. Hall JG, Allanson JE, Gripp KW, Slavotinek AM. Handbook of Physical Measurements. Oxford University Press 2007.

23. Norland Medical Systems pDEXA Owner's Manual. Norland Medical Systems, Madison WI, USA.

24. Lee PH, Macfarlane DJ, Lam TH, Stewart SM. Validity of the international physical activity questionnaire short form (IPAQ-SF): a systematic review. Int J Behav Nutr Phys Act 2011; 8: 115.

25. Biernat E, Stupnicki R, Gajewski AK. International Physical Activity Questionnaire (IPAQ) - Polish version. Wychow Fiz Zdr 2007; 6-7: 4-9.

26. Haskell WL, Lee IM, Pate RR, Powell KE, Blair SN. Physical activity and public health: updated recommendation for adults from the American College of Sports Medicine and the American Heart Association. Med Sci Sports Exerc 2007; 39: 1423-34.

27. World Health Organization: Global recommendations on physical activity for health 2010.

28. Drenjancevic I, Davidovic Cuetko E. Influence of physical activity to bone metabolism. Med Glas Ljek komore Zenicko-doboj kantona 2013; 10: 12-9.

29. Tucker LA, Fosson E, Bailey BW, Le Cheminant JD. Is the dose-response relationship between body mass and hip bone mineral density in women influenced by diet, 
physical activity, or menopause? Am J Health Promot 2014; $28: 325-7$.

30. Kumar A, Mittal S, Orito S, Ishitani K, Ohta H. Impact of dietary intake, education, and physical activity on bone mineral density among North Indian women. J Bone Miner Metab 2010; 28: 192-201.

31. Kim KM, Choi SH, Lim S, et al. Interactions between dietary calcium intake and bone mineral density or bone geometry in a low calcium intake population (KNHANES IV 2008-2010). J Clin Endocrinol Metab 2014; 99: 2409-17.

32. Saravi FD, Sayegh F. Bone mineral density and body composition of adult premenopausal women with three levels of physical activity. J Osteoporos 2013; 2013: 953271.

33. Gracia-Marco L, Rey-López JP, Santaliestra-Pasías AM, et al. Sedentary behaviours and its association with bone mass in adolescents: the HELENA cross-sectional study. BMC Public Health 2012; 12: 971.

34. Chastin SFM, Mandrichenko O, Skelton DA. The frequency of osteogenic activities and the pattern of intermittence between periods of physical activity and sedentary behaviour affects bone mineral content: the cross-sectional NHANES study. BMC Public Health 2014; 14: 4.

35. Bailey CA, Brooke-Wavell K. Optimum frequency of exercise for bone health: randomised controlled trial of a high-impact unilateral intervention. Bone 2010; 46: 1043-9.

36. Andreoli A, Celi M, Volpe SL, Tarantino U. Long-term effect of exercise on bone mineral density and body composition in post-menopausal ex-elite athletes: a retrospective study. Eur J Clin Nutr 2012; 66: 69-74.

37. Li HL, Zhu HM. Relationship between the age of menarche, menopause and other factors and postmenopause osteoporosis. Zhonghua Fu Chan Ke Za Zhi 2005; 40: 796-8.

38. Parker SE, Troisi R, Wise LA, et al. Menarche, menopause, years of menstruation, and the incidence of osteoporosis: the influence of prenatal exposure to diethylstilbestrol. J Clin Endocrinol Metab 2014; 99: 594-601.

39. Gallagher JC. Effect of early menopause on bone mineral density and fractures. Menopause 2007; 14: 567-71.

40. Compston JE, Flahive J, Hosmer DW, Watts NB, Siris ES. Relationship of weight, height, and body mass index with fracture risk at different sites in postmenopausal women: the Global Longitudinal Study of Osteoporosis in Women (GLOW). JBMR 2014; 29: 487-93.

41. Lo H, Kuo D, Chen Y. Impact of beverage consumption, age, and site dependency on dual energy X-ray absorptiometry (DEXA) measurements in perimenopausal women: a prospective study. Arch Med Sci 2017; 13: 1178-87.

42. Baczyk G, Samborski W, Jaracz K. Evaluation of the quality of life of postmenopausal osteoporotic and osteopenic women with or without fractures. Arch Med Sci 2015; 12: 819-27.

43. Simona D, Kleyera A, Englbrecht $M$, et al. A comparative analysis of articular bone in large cohort of patients with chronic inflammatory diseases of the joints, the gut and the skin. Bone 2018; 116: 87-93.

44. Nazari Soltan Aahmad S, Nourollahi S, Kazerouni F, et al. Investigation of the relation between bone mass density and serum preptin levels in pre- and postmenopausal women. J Bone Miner Metab 2018; 36: 710-5. 